\title{
BIOÉTICA: UN DISCURSO INTERSTICIAL
}

\author{
Fernando Lolas Stepke
}

El presente número de Acta Bioethica es un vivo testimonio de la posición de interfaz que ocupa el discurso bioético y recoge artículos de diversa factura, desigual alcance y estilos diferentes.

Desde que la revista parece haber consolidado su posición como referencia de la comunidad bioética en los países de América Latina, el Caribe, Estados Unidos y Europa, acrecentada por su reciente inclusión en Science Citation Index, el número de manuscritos no solicitados y la demanda por publicar en sus páginas ha crecido. Como siempre, no se consolidan los límites de una disciplina por simple imposición de temas. Se establecen, en realidad, cuando se constituye una comunidad de reflexión y de prácticas. Confiamos que Acta Bioethica pueda contribuir a ese desarrollo.

En este número se abarca un ampio espectro de temas. Algunos se relacionan con la ciencia y la investigación, otros con la asistencia sanitaria, algunos con la enseñanza. Tenemos aportes empíricos, ensayos, reflexiones, y una amplia representatividad geográfica. Como es habitual, la edición incluye comentarios de libros y noticias sobre publicaciones recientes. La vitalidad de una publicación como Acta se mide por las citaciones que sus trabajos reciben y en tal sentido es grato comprobar que el número de ellas crece día a día.

De todas formas, sigue la bioética constituyendo lo que cabe llamar un discurso "intersticial". Esto significa, un discurso "entre" los saberes constituidos y consolidados en la institucionalidad universitaria y asistencial. En su aspecto positivo, esta intersticialidad significa que se interpelan muchas disciplinas, en ejercicios que pueden ser multi, inter o transdisciplinarios. En su aspecto negativo, da pábulo para superficiales afirmaciones, villanía intelectual y audacias que a veces cabe rotular de auténtico bandolerismo académico. Se erigen autoridades y gurúes por todas partes, se usa y abusa del prestigio de instituciones internacionales, se realizan gestos que parecen tener significado pero que en el fondo son maneras disfrazadas de ejercer poder o alcanzar posiciones políticas.

Pero lo que la bioética llegará a ser en el horizonte intelectual latinoamericano pasará sin duda por la superación de aquellas distinciones sin diferencias que algunos establecen con espurios fines y dudosas intenciones. Algún día llegará en que el trabajo en bioética sea reconocido y valorado, y no será simplemente porque alguien se erige en experto sino porque la comunidad profesional advierte que el discurso bioético es un indispensable componente del trabajo serio, responsable y coherente que se requiere. 